\title{
LAS “BUENAS FAMILIAS" DE BILBAO Y EL PODER LOCAL EN EL PRIMER FRANQUISMO (1937-1959)
}

\section{ANTONIO PÉREZ EMBEITA}

Madrid, 2019, Sílex Ediciones, 237 páginas

En estos últimos años estamos asistiendo a una interesante renovación en los análisis históricos sobre la dictadura franquista. Si en décadas anteriores habían primado los estudios de carácter biográfico sobre sus más relevantes personalidades, empezando por el propio dictador, el estudio de los cambios de su política internacional o económica o acerca de la caracterización tipológica del régimen, ahora parece que tienen más interés otras cuestiones que inciden directamente en lo que podríamos llamar el "franquismo a ras de suelo", esto es, cómo se construye en pueblos y ciudades la "cultura de la Victoria" que se promovió desde el poder, la represión sobre los opositores en pueblos y ciudades, las miserables condiciones de vida de las clases populares en los años del estraperlo o quiénes formaban las élites políticas que sostuvieron a la dictadura en las instituciones locales o provinciales. Precisamente en esta última línea de investigación, abierta en 1996 con el renovador trabajo de Glicerio Sánchez Recio sobre los “cuadros políticos intermedios” del régimen, es en la que hay que insertar este libro de Antonio Pérez sobre las "buenas familias" bilbaínas y su influencia en el Ayuntamiento de la capital vizcaína, durante lo que se ha venido en llamar "el primer franquismo".

Se trata de una versión resumida de la tesis doctoral que su autor presentó en el año 2019 en la Universidad del País Vasco bajo la dirección del profesor Mikel Urquijo, y que claramente se ha beneficiado de toda la relevante trayectoria que el grupo de Investigación "Biography \& Parliament" de esta universidad viene realizando en el ámbito de la historiografía de la biografía y la prosopografía, tanto en sus contenidos, como en sus aspectos metodológicos. $\mathrm{Y}$ es que lo que se hace en este libro es un completo análisis prosopográfico del personal político que gestiona el Ayuntamiento de Bilbao desde la entrada de las tropas nacionales en la villa al comienzo del verano de 1937 hasta el emblemático año de 1959, tan importante en la evolución económica y política de la dictadura. En definitiva, lo que se pretende es "radiografiar" a los hombres - porque no hubo ninguna mujer- que defendieron y construyeron el franquismo en Bilbao en los momentos más sombríos de esta 
dictadura, distinguiendo claramente a los que llama "concejales rasos" de los alcaldes y tenientes de alcalde que llevaron el peso de la gestión municipal y claramente relacionados con el núcleo poderoso de las llamadas "familias de Neguri".

Después de un breve capítulo en el que se explica el marco legal en el que se movieron los primeros Ayuntamientos franquistas, como fue la Ley de Bases de Régimen Local de 1945, que fijaron unas manipuladas representaciones por tercios -sindical, familiar y de entidades-, es en el capítulo tercero en el que se realiza el análisis proposográfico sobre las corporaciones bilbaínas que se suceden entre 1937 y 1959, que constituye el núcleo central de la investigación. ¿Cuál es el retrato socioprofesional de estos 112 ediles y alcaldes franquistas? La de empresario es la actividad económica más repetida seguida por la de abogado y la edad media de estas corporaciones fue de 44,6 años, es decir, personas que ya tenían una experiencia vital o política contrastada (p. 41). Pero hay un dato que pone en evidencia el carácter elitista de las mismas y su alejamiento de lo que era la realidad cotidiana de la mayoría de los habitantes de la ciudad: un 67 por ciento de estos cargos municipales tenía estudios superiores, en una época en los que sólo una minoría de privilegiados podía acceder a la universidad y, particularmente, a los dos centros de educación superior que había entonces en Bilbao, como eran la Universidad de Deusto y la Escuela Especial de Ingenieros Industriales.

En el aspecto político, cuatro fueron los partidos o ideologías predominantes en este Ayuntamiento del primer franquismo: la Comunión Tradicionalista, Falange, Renovación Española y, por último, lo que se vino en llamar el Movimiento Nacional como partido único del régimen. Llama la atención la relevancia de grupo alfonsino de Renovación Española, marginal en los años republicanos pero muy implantado en la burguesía industrial de la zona y del que saldría el primer alcalde franquista de la ciudad- José María de Areilza- y el más longevo, que fue Joaquín Zuazagoitia. Y en cuanto a cantidad, también destaca la igualdad en el número de ediles de Falange y los carlistas a lo largo de estos años, lo que, como bien indica Antonio Pérez, fue una característica del franquismo: repartir de forma equilibrada el poder entre sus "familias" políticas", y que generó como resultado en el ayuntamiento bilbaíno una "sobrerrepresentación” de Falange (p. 53). No obstante, con el paso de los años, fue disminuyendo la representación de estos grupos anteriores a la guerra y se consolidó la de los que ya procedían del Movimiento Nacional que no tenían vinculaciones partidistas previas a la dictadura, resultado de la consolidación del régimen dictatorial.

En el capítulo cuarto del libro se analiza la gestión de estas corporaciones, con especial atención a la reconstrucción de los puentes que fueron destruidos durante la guerra, todos ellos marcados por los continuos retrasos en su ejecución. Se comenta a continuación 
el proceso de depuración al que se vieron sometidos los funcionarios municipales, desde que llegó Areilza a la alcadía y que dio como resultado la incoación de más de dos mil expedientes y la destitución de más del 58 por ciento de los empleados, apoyándose en este apartado el autor en las completas investigaciones de Aritz Ipiña. Para sustituir a los cesados, las autoridades bilbaínas acudieron a los excombatientes del bando franquista, con tanto celo que la "comisión provincial" que los representaba llegó a felicitar al ayuntamiento por haber cubierto con ellos el doble de las vacantes marcadas por la ley (p. 99). Estaba claro, como señala Antonio Pérez, que los puestos de funcionarios formaron parte del botín de guerra, "premiándose con ellos a los ganadores y, por el contrario, dejando sin sustento a los vencidos" (p. 100).

La propaganda también estuvo presente en las actividades de estas corporaciones franquistas y se manifestó, entre otros aspectos, en el cambio de nombre de los puentes, en el callejero, convirtiendo - por citar un ejemplo- la hasta entonces llamada avenida de Sabino Arana en la nueva avenida de José Antonio, incluso se llegó a colocar un busto del fallecido general Mola en el Arenal bilbaíno, que fue destruido por una bomba en 1946, pero que repuesto se mantuvo hasta los años de la Transición. Incluso se llegó a crear la Medalla de Hierro de la Villa para premiar a los combatientes franquistas y, sin ningún pudor y en sentido contrario, se desmanteló el monumento dedicado a los defensores liberales de Bilbao durante el sitio carlista de 1874. Sin embargo, fue el apartado de las obras e infraestructuras donde esto gobernantes franquistas mostraron sus auténticas limitaciones y su ineptitud como gestores, especialmente en los problemas de saneamiento y en la resolución del problema de la vivienda.

Cuando estos ediles franquistas llegaron al ayuntamiento se encontraron con una ciudad cuyo ensanche no disponía de saneamiento y donde las "aguas negras" de buena parte de las fábricas se vertían directamente en la Ría, provocando que ésta estuviera permanentemente contaminada. ¿Qué hicieron estos alcaldes franquistas para resolver el problema?, nada. Lo dice bien claro Antonio Pérez. “el saneamiento no sólo no mejoró, sino que incluso fue a peor debido a la falta de soluciones y al aumento de la población, que acrecentaba el problema” (p. 134). Y lo mismo ocurría con el abastecimiento de agua potable: "Bilbao era una ciudad con frecuentes lluvias en la que, sin embargo, los habitantes tenían que convivir con la falta de agua", porque no fue hasta el año 1958 cuando el Ayuntamiento aprobó un plan para la mejora de este abastecimiento. No obstante, donde la ineficacia alcanzo su mayor nivel fue en la problemática de la vivienda y los asentamientos chabolistas que rodeaban la ciudad. Aunque nada más terminada la guerra, en 1939, se creó un Instituto 
de Viviendas Municipales para hacer frente a esta situación, su falta de capacidad económica y de gestión hizo que en la década de los años cincuenta el problema se convirtiera en "insostenible". Ante este fracaso, el alcalde Zuazagoitia tuvo que acudir al Instituto Nacional de la Vivienda del gobierno central, que en 1952 aprobó el llamado "Plan Vizcaya" que pretendía construir 7.500 casas, pero en toda la provincia. Por esta razón, el chabolismo siguió aumentando durante toda la década de los años cincuenta y en la prensa de la época se decía que unas quince mil personas eran las que habitan en estos núcleos insanos e ilegales situados en las laderas que circundaban Bilbao. Y en los años sesenta las chabolas continuaron formando parte del paisaje de la ciudad (p. 147). Todo ello mientras que sus alcaldes, incapaces de resolver estas perentorias necesidades, sólo se obsesionaban porque los presupuestos municipales se liquidaran con superávit.

El último capítulo del libro Antonio Pérez lo dedica a hacer un análisis comparativo de esta gestión con lo que ocurre en otras ciudades como Vitoria, San Sebastián, Barakaldo, Pamplona, Palencia, Santander y Barcelona, resaltando las semejanzas y diferencias que había en cuanto a la militancia política de sus gobernantes, la duración temporal de sus corporaciones o la influencia que sus élites económicas y sociales tenían en la vida municipal. Con este oportuno marco comparativo y con un completo anexo que incluye las composiciones completas de las corporaciones que fueron cambiando entre 1937 y 1959 se cierra un libro.

Con un gran rigor metodológico, estamos ante un completo trabajo que nos permite conocer mejor a las élites políticas que gobiernan el Ayuntamiento de Bilbao del primer franquismo, las que no tenían reparos en gastar lo que hiciera falta en propaganda en favor de la dictadura, mientras que mucha gente corriente y trabajadora malvivía en chabolas o en unas viviendas insalubres, que quedaron sin erradicar después de más de veinte años de gestión municipal.

\section{Diego Caro Cancela}

Universidad de Cádiz 